\title{
TEORIA DAS DECISÕES: UM ESTUDO DO MÉTODO LEXICOGRÁFICO.
}

\author{
Eduardo Picanço Cruz \\ Carlos José Guimarães Cova
}

\section{RESUMO}

Diariamente, gerentes do mundo inteiro estão concentrando esforços no sentido de assegurar uma decisão correta. Essa busca se dá devido ao alto grau de risco que envolve o processo, principalmente pelas grandes somas de capital em "jogo". Dessa forma, é preciso minimizar os ruídos em um processo decisorial, principalmente no que se refere às falhas humanas envolvidas. 0 presente trabalho trata da questão da tomada de decisão em termos de qualidade do julgamento e envolve, principalmente, a metodologia conhecida como Lexicográfica. 0 texto chama atenção para que o decisor não incorra em enganos durante o processo de escolha, principalmente quando este gasta mais atenção com ao método utilizado do que com o problema propriamente dito.

Palavras-chave: Teoria da decisão. Multicritério. Escolhas. Métodos de decisão.

\begin{abstract}
On a daily basis, managers of the entire world are concentrating efforts to assure an apropriate decision. This search is due to the high risk that involve the process, mainly by the great amount of money in "gamble". So, it is necessary to minimize the noises in a decisorial process, mainly as regards the humans fails involved. The present papper relates the question of the decision maker in terms of quality of the judgment and involves, mainly, the Lexicografic methodology. The text calls attention for the decisor doesn't make mistakes clear no in his choice, mainly when he spent more attention with the method used instead of the problem properly said.
\end{abstract}

Keywords: Decison theory. Multicriteria. Choices. Decison Methods. 


\section{INTRODUÇÃO: METODOLOGIAS MULTICRITÉRIO}

Verifica-se uma tendência, nos tempos atuais, no sentido de que uma grande parcela das decisões que são tomadas no contexto empresarial envolve questões econômico-financeiras, que têm como base de fundamentação alguns aspectos estritamente quantitativos, traduzidos por valores monetários, obtidos a partir de projeções de fluxos de caixa periódicos e devidamente descontados por taxas arbitrárias. Não obstante, a teoria da decisão recomenda que tais escolhas devam ser fundamentadas também em outros aspectos, como os qualitativos, que não são menos importantes do que os anteriores, mas que se prestam à tentativa de explicitar e traduzir o ambiente nebuloso no qual as empresas atuam e estão inseridas, mas que, via de regra, não é internalizado na análise. Tal circunstância pode vir a se constituir em uma determinante fonte de fracasso ou de inconsistência de um projeto, que porventura tenha sido escolhido com base em critérios estritamente quantitativos. Por exemplo, no caso de aceitação de um projeto para a construção de uma usina hidrelétrica, que, para ser construída, exigiria a inundação de uma reserva indígena, alguns aspectos não mensuráveis monetariamente não seriam incorporados na análise tradicional. Nesse sentido, seria preciso valorar de alguma forma quanto custa a mata nativa e a biodiversidade que será degradada? Qual o valor que deve ser atribuído aos animais? Como precificar estes bens fora do mercado para inserir em fluxos de caixa? Como quantificar a repulsa dos funcionários ou outros aspectos intangíveis, para que se possa optar por uma determinada alternativa?

Nesse sentido, conforme ensina Rezende (2003), é preciso apresentar algumas definições acerca dos seguintes conceitos: dado; informação; conhecimento e decisão. 0 dado é um elemento puro, quantificável, sobre determinado evento. A informação, por sua vez, consiste num conjunto de dados analisados e contextualizados. 0 conhecimento pode ser entendido como sendo a habilidade de criar um processo mental que descreva um determinado objeto e indique as ações à implementar ou as decisões à tomar. Por fim, a decisão é o uso explícito do conhecimento. Ainda de acordo com a autora, o processo de geração do conhecimento é o resultado de um encadeamento de etapas, no qual uma informação é comparada a outras e então combinadas em muitas ligações úteis e com significado. Isto implica em que o conhecimento depende dos valores e da experiência dos atores envolvidos em seu processo de geração, o que reforça a importância dos aspectos subjetivos na sua geração.

Dessa forma, para que se possa contemplar a introdução destes aspectos no contexto da decisão, faz-se necessário o desenvolvimento de metodologias que possam, ao mesmo tempo, contemplar ambas as dimensões, ou seja, tanto aquelas de caráter quantitativo, bem como as que possuam natureza qualitativa, de tal forma que o decisor possa inserir aspectos ligados ao preço e custo mas também beleza, conforto, aceitabilidade, entre outros critérios. A sofisticação dos modelos deu-se com o surgimento da pesquisa operacional, dessa ciência são oriundas as chamadas metodologias multicritério de apoio à decisão (Multicriteria Decisions MCDA) , que formam um conjunto de técnicas que têm a finalidade de investigar um número de alternativas, considerando múltiplos critérios e objetivos em conflito (GOMES, 1999).

No início dos anos 70, na Universidade da Carolina do Sul - EUA, foi realizada uma conferência sobre o tema que, segundo Bana e Costa (1993), começou a tomar forma e a organizar-se numa "comunidade científica, antes dispersa, interessada pelo domínio do multicritério". Em 1975, Bernard Roy, um dos principais pesquisadores do assunto, organiza o encontro Euro Working Group on Multicriteria Aid for Decisions na cidade de Bruxelas. No mesmo ano foi organizada uma conferência que mais tarde formou a International Society on Multiple Criteria Decision Making" (BANA E COSTA et alii, 1995). Estes dois encontros 
marcam as origens das duas escolas: a perspectiva decision making da escola americana da utilidade multi-atributo e a corrente aide à la décision da escola francesa. Gomes et alii (2002) afirmam que "a escola francesa é baseada em relações de prevalência" e nela se destacam os métodos das famílias ELECTRE e PROMETHEE, já a escola americana "reduz os vários critérios a um critério síntese, na grande maioria das vezes através de uma soma ponderada".

Os mesmos autores destacam ainda, para o caso da escola americana os seguintes métodos: AHP, TODIM, MACBETH e UTA. A literatura apresenta ainda duas diferenças clássicas em relação aos métodos de avaliação multicritério: os problemas multiatributo e multiobjetivo, onde o primeiro lida com alternativas discretas e o segundo trata de um espaço contínuo de alternativas.

\section{CONCEITOS USADOS NA TOMADA DE DECISÃO}

Para permitir um correto entendimento acerca deste assunto amplo e multifacetado, convém que sejam apresentadas algumas considerações de caráter conceitual, a fim de uniformizar o conteúdo ôntico da terminologia empregada. Nesse sentido, serão apresentadas algumas definições importantes no campo da tomada de decisão.

Critérios: são os balizadores de uma decisão, ou seja, são os instrumentos que permitem a comparação das ações em relação a pontos de vista particulares. Dessa forma, um critério seria uma expressão qualitativa ou quantitativa de um ponto de vista utilizado na avaliação das alternativas.

Roy e Bouyssou (1993) apresentam as seguintes regras, para uma correta definição dos critérios:

(1) Descrição completa do problema: os critérios devem ser abrangentes;

(2) Coerência: se uma alternativa é melhor, individualmente, em todos os critérios, no total geral ela também deve ser melhor;

(3) Não Redundância: devemos eliminar os critérios fúteis.

Problemáticas de Apoio à Decisão: estão no contexto da decisão e referem-se à questões que são apresentadas para delinear o contorno da decisão. Roy e Bouyssou (1993) apresentam três problemáticas de apoio à decisão. São elas:

- Problemática de seleção - objetiva recomendar a escolha de uma alternativa. Usada em decisões como qual carro comprar? Onde passar as próximas férias? Qual filme assistir?;

- Problemática de ordenação - objetiva criar uma ordem entre as alternativas. Por exemplo os campeonatos de fórmula 1, oferecer o ranking das melhores escolas para se estudar;

- Problemática de alocação em classes - objetiva recomendar a triagem das alternativas em categorias preestabelecidas, podendo ser ordenadas ou não. Usadas, por exemplo, para distribuir os candidatos que fizeram vestibular nos grupos de aprovados para o $1^{\mathrm{o}}$ semestre, aprovados para o $2^{\circ}$ semestre, aprovados mas aguardando classificação e reprovados.

Os problemas de alocação em classe ou ordem podem ser usados para os casos de seleção, aliás é essa a proposta de Simom (1974). Porém, o inverso nem sempre ocorre, pois muitas metodologias de escolha destacam tão somente a primeira colocação dentre as alternativas, não se preocupando em criar uma seqüência de alternativas também válidas. Por exemplo, 
quando se tem que escolher dentre 6 alternativas possíveis, o "jogo de dados" pode ser uma metodologia usada para essa decisão. Nesse caso, basta saber o número vitorioso e ignorar as alternativas que sobraram.

Estrutura de preferências: traduz o grupo de relações binárias (para A, B e C seriam AB, AC e BC, por exemplo) possíveis sobre o conjunto de alternativas. Roy e Bouyssou (1993) apresentam quatro relações fundamentais: Indiferença: a I b; Preferência Estrita: a P b; Preferência Fraca: a Q b; Incomparabilidade: a R b. Essas estruturas são utilizadas nos problemas onde o julgador vai comparar as alternativas ao invés de dar notas isoladas para cada uma delas.

Matriz de Decisão: é uma das formas para se representar a relação entre os critérios e as alternativas. Podemos apresentar os seguintes modelos:

- Para julgamentos por notas (de zero a dez, por exemplo):

Alternativas: A1, A2, A3 ; Critérios: C1, C2, C3 . Logo, a Matriz será:

Tabela 1: Matriz de decisão

\begin{tabular}{|l|l|l|l|}
\hline & C1 & C2 & C3 \\
\hline A1 & $\mathrm{a}_{11}$ & $\mathrm{a}_{12}$ & $\mathrm{a}_{13}$ \\
\hline $\mathbf{A 2}$ & $\mathrm{a}_{21}$ & $\mathrm{a}_{22}$ & $\mathrm{a}_{23}$ \\
\hline $\mathbf{A 3}$ & $\mathrm{a}_{31}$ & $\mathrm{a}_{32}$ & $\mathrm{a}_{33}$ \\
\hline
\end{tabular}

Fonte: Desenvolvimento Próprio

Dessa forma, para cada ajj será considerada uma nota, ou seja, a11 será a nota da alternativa A1 no critério $\mathrm{C} 1$ e assim por diante.

- Para julgamentos feitos por análise comparativa:

Alternativas: A1, A2, A3 ; Critérios: C1, C2, C3 . Logo, as Matrizes serão:

Tabela 2: Matriz de decisão II

\begin{tabular}{|c|c|c|c|}
\hline \multicolumn{4}{|c|}{ Critério C1 } \\
\hline & A1 & A2 & A3 \\
\hline A1 & I & $\mathrm{a}_{12}$ & $\mathrm{~A}_{13}$ \\
\hline A2 & $\mathrm{a}_{21}$ & $\mathrm{I}$ & $\mathrm{A}_{23}$ \\
\hline $\mathbf{A 3}$ & $\mathrm{a}_{31}$ & $\mathrm{a}_{32}$ & $\mathrm{I}$ \\
\hline
\end{tabular}

\begin{tabular}{|c|c|c|c|}
\hline \multicolumn{4}{|c|}{ Critério C2 } \\
\hline & A1 & A2 & A3 \\
\hline A1 & I & $\mathrm{a}_{12}$ & $\mathrm{a}_{13}$ \\
\hline $\mathbf{A 2}$ & $\mathrm{a}_{21}$ & $\mathrm{I}$ & $\mathrm{a}_{23}$ \\
\hline $\mathbf{A 3}$ & $\mathrm{a}_{31}$ & $\mathrm{a}_{32}$ & $\mathrm{I}$ \\
\hline
\end{tabular}

\begin{tabular}{|c|c|c|c|}
\hline \multicolumn{4}{|c|}{ Critério C3 } \\
\hline & A1 & A2 & A3 \\
\hline A1 & I & $\mathrm{a}_{12}$ & $\mathrm{a}_{13}$ \\
\hline A2 & $\mathrm{a}_{21}$ & $\mathrm{I}$ & $\mathrm{a}_{23}$ \\
\hline $\mathbf{A 3}$ & $\mathrm{a}_{31}$ & $\mathrm{a}_{32}$ & $\mathrm{I}$ \\
\hline
\end{tabular}

Fonte: Desenvolvimento Próprio

\section{FASES DO PROCESSO}

Dias et alii (1996) apresentam as duas fases dos processos de apoio à decisão. A primeira fase consiste na estruturação, e a mesma representa cerca de $80 \%$ do total do tempo despendido na caracterização do problema, segundo afirmam Bana e Costa et alii (2000). Nessa fase, estão presentes a formulação do problema e a identificação dos objetivos. Para Gomes et alii (2000), na estruturação há o objetivo de "identificar, caracterizar e organizar os fatores considerados relevantes no processo de apoio à decisão". Além disso, essa fase envolve a definição dos objetivos do decisor, identificação das alternativas possíveis e estabelecimento dos critérios, entre outras atividades. Exemplo: 
No problema da compra da viagem poderíamos ter duas situações:

A - Onde viajar nas próximas férias. \{foco mal definido: pouca clareza\}

B - Onde viajar nas próximas férias, submetido as seguintes condições:

- Desde que seja num raio de até $100 \mathrm{~km}$ de distância da residência da família;

- Desde que atenda ao lazer de uma família (composta por 02 adultos e 02 crianças);

- Não pode ser em uma região que tenha vias sem pavimentação, pois o carro da família não suportaria o desgaste adicional;

- O local deve dispor de estabelecimentos que sirvam pensão completa;

- A família tem restrição orçamentária de $\mathrm{R} \$ 5.000,00$ para o passeio.

A situação B está melhor definida, porém, a estruturação deve ser ainda mais detalhada. Não obstante, para exemplos didáticos, usaremos apenas a frase "para aonde viajar" ou "compra de uma carro", mesmo sabendo ser esta caracterização a tradução de um problema mau definido.

Já a fase de Avaliação, segundo Gomes et alii (2000), "objetiva a aplicação de métodos de análise multicritério para apoiar a modelagem das preferências e sua agregação". Para o autor, a fase pode ser dividida em duas: a avaliação parcial das alternativas segundo cada critério; e a fase de agregação dessas avaliações parciais, conhecida como avaliação global. É nessa etapa que serão utilizados os métodos adiante descritos.

\section{PARTICULARIDADES DOS JULGAMENTOS}

Em uma investigação inicial, via de regra, as possibilidades de se executar um julgamento não são estruturadas de maneira didática. Assim, faz-se necessário atuar em duas linhas de abordagem: as possibilidades de se fazer escolhas de alternativas nas pesquisas de opinião, que não deixam de ser formas de julgamento; e os métodos de auxílio multicritério à decisão que apresentam diferentes formas de se julgar. Com relação às pesquisas de marketing, encontram-se propostas para que o entrevistado escolha dentre duas possibilidades de resposta (sim ou não; gosto ou não gosto; conheço ou não conheço, por exemplo). Esse tipo de julgamento interessa parcialmente ao tomador de decisão, pois indica qual a orientação do entrevistado. Porém, como este não atribui um valor numérico que permita valorar objetivamente sua escolha, fica sobremaneira difícil o estabelecimento de uma relação métrica (uma escala) entre duas respostas. Dessa forma, elas são usadas nos casos em que o respondente é colocado diante da necessidade de avaliar se uma alternativa é viável ou não, ou seja, é a chamada relação binária: zero ou um. Outra possibilidade é a escolha dentre várias possibilidades de resposta, como no caso: Onde você trabalha? ( )Indústria, ( )Comércio, ( JOngs, ( )Bancos, ( )Outros. Seguindo o mesmo raciocínio anterior, o julgador apenas informa sua opção. Em ambos os casos, a forma de se descobrir qual é a alternativa preferida se dá por uma soma simples dos votos que cada uma recebeu. Assim, só é possível fazer uma escala entre as alternativas ao final do processo.

Nos casos das perguntas abertas, sobra para o tabulador a difícil tarefa de interpretar as preferências ou registrar as respostas repetidas muitas vezes. Porém, como nem sempre os entrevistados usam os mesmos adjetivos para qualificarem suas preferências, podem ser identificados alguns erros de tabulação, tais como, por exemplo, como no caso de dois 
questionários que apresentam as seguintes características: Qual o seu lazer predileto? 0 primeiro responde que é cinema e o segundo filmes. São descrições que devem ser tabuladas juntas, pois entende-se que ambos referem-se ao ato de assistir filmes, ou separadas, pois a segunda resposta poderia estar relacionada a uma locação de filme ou mesmo à programação da televisão?

Existem ainda metodologias que procuram refinar a análise. Uma variante possível de ser adotada consiste na criação de uma ordem entre as respostas. Este método decorre dos estudos do matemático Jean-Charles Borda e tem sido descrito por vários autores, tais como, por exemplo, Cruz e Lopes (2005). Trata-se de uma escala individual, na qual os pontos atribuídos em cada resposta serão somados para permitir a identificação das alternativas mais desejadas, bem como das mais rejeitadas.

Em relação aos métodos multicritério, foram identificadas duas possibilidades:

- Julgamentos individuais: quando o avaliador oferece uma nota a cada alternativa à luz de cada critério. É o caso tradicional da escolha da melhor escola de samba, no desfile do carnaval, quando os jurados esperam a agremiação passar, e analisam seu desempenho, atribuindo um valor para uma série de quesitos. Normalmente, podem ser impostas algumas barreiras para evitar irregularidades, tais como, por exemplo, a limitação de uma nota mínima não nula, a votação em escalas (de 0,5 em 0,5 ) ou eliminação nas notas extremas;

- Julgamento par-a-par: o avaliador é instado a separar seu julgamento em pares de preferência, indicando o grau da ordem. Assim, ao avaliar entre três possibilidades de investimento ( $A, B$ e $C$ ) seriam julgados os pares $A B, A C$ e $B C$. Para processos com quatro alternativas seriam feitos 6 julgamentos ( $A B, A C, A D B C, B D$ e $C D)$. Percebe-se que, quanto maior a complexidade do problema em termos de quantidade de alternativas, maior será a dificuldade de julgar.

A primeira tem sido utilizada principalmente nos métodos na família Electre de auxílio à decisão, enquanto o julgamento par-a-par está difundido em métodos como o MACBETH de Bana e Costa e Vansnick ou no Método da Análise Hierárquica de Saaty.

\section{COERÊNCIA DOS JULGAMENTOS}

0 termo coerência ou consistência está relacionado à uma das condições de racionalidade do julgamento, que é evidenciada por meio da transitividade. A primeira forma percebê-la é através do julgamento, ou seja: Se A é melhor que B, e B é melhor que $C$, consequentemente, $A$ é melhor que $C$. Se a resposta for diferente $C$ melhor que $A$ ou $C$ igual a $A$ o julgador foi incoerente.

A segunda forma de ser incoerente está no grau do julgamento, ou seja: Se A é muito melhor que $B$, e B é muito melhor que $C$, logo, A é extremamente melhor que $C$. A incoerência ocorrerá caso o julgador opine que A é um pouco melhor que C. A incoerência está presente em todas as competições esportivas, por exemplo, no futebol, em um campeonato de pontos corridos, é bem provável que um time $\mathrm{A}$ vença o $\mathrm{B}$, que o $\mathrm{B}$ vença o $\mathrm{C}$ e que o $\mathrm{C}$ consiga vencer o $\mathrm{A}$. Isso torna o resultado final de qualquer campeonato um espaço de discussões intermináveis.

\section{O MÉTODO LEXICOGRÁFICO}

A palavra lexicografar significa dicionarizar, ou seja, dispor as opções por alguma ordem lógica de apresentação. Dessa forma, o método exige a definição das alternativas e dos 
critérios, além disso, o julgador deverá propor uma ordenação dos mesmos, do que ele considera o mais importante até o último. 0 método consiste em avaliar todas as alternativas focando-se exclusivamente para o critério mais importante. A alternativa que ganhar é considerada como sendo a vencedora, ou, se houver empate na $1^{\text {a }}$ colocação, essas alternativas serão encaminhadas sozinhas para o desempate, que será feito com base no próximo critério em importância. Nesse sentido, os critérios menos importantes só serão considerados na medida em que ocorra empate nos critérios mais relevantes.

Exemplo: Compra de Carro. Alternativas: GOL, CORSA e PALIO. Critérios: Preço; Beleza; Conforto. Possibilidade 1: Para quem prioriza o Preço $\rightarrow$ Beleza $\rightarrow$ Conforto

Tabela 3: Matriz de decisão III

\begin{tabular}{|l|c|c|c|}
\hline & Preço & Beleza & Conforto \\
\hline GOL & 8 & 7 & 10 \\
\hline CORSA & $\mathbf{1 0}$ & $\mathbf{7}$ & 7 \\
\hline PALIO & $\mathbf{1 0}$ & $\mathbf{7}$ & $\mathbf{9}$ \\
\hline
\end{tabular}

Fonte: Desenvolvimento Próprio

Traduzindo: o CORSA e o PALIO avançam no primeiro critério e o GOL é eliminado. Em seguida, as duas alternativas ainda se mantêm válidas porque ficam empatadas e com notas boas. No último critério o PALIO vence o CORSA. Nesse caso a melhor alternativa é o PALIO. Possibilidade 2: Para quem prioriza o Conforto $\rightarrow$ Beleza $\rightarrow$ Preço

Tabela 4: Matriz de decisão IV

\begin{tabular}{|l|c|c|c|}
\hline \multicolumn{4}{|c|}{ NOTA } \\
\hline & Preço & Beleza & Conforto \\
\hline GOL & 8 & 7 & $\mathbf{1 0}$ \\
\hline CORSA & 10 & 7 & 7 \\
\hline PALIO & 10 & 7 & 9 \\
\hline
\end{tabular}

Fonte: Desenvolvimento Próprio

Nesse segundo caso (considerando-se os mesmos julgamentos, só alterou-se a prioridade dos critérios) a melhor alternativa é o GOL, pois ganha do CORSA e do PALIO logo no $1^{\circ}$ critério.

O método é usado nas olimpíadas pois a classificação geral se faz através do número de medalhas de ouro. Se houver empate utiliza-se o número de medalhas de prata e, se persistir o empate, serão consideradas as medalhas de bronze. Existe um exemplo interessante para se discutir o método que é a partida de Voley. Supondo uma disputa entre Brasil e Cuba: 1ㅇ SET: Brasil 25 X 23 Cuba; 2ํ SET: Brasil 0 X 25 Cuba; 3ํ SET: Brasil 25 X 23 Cuba; 4ㅇ SET: Brasil 0 X 25 Cuba; 5 SET: Brasil 15 X 13 Cuba. Notem que o Brasil ganhou, mas Cuba foi quem marcou mais pontos. Nesse caso, pergunta-se: QUEM FOI MELHOR? 0 método lexicográfico traz uma reflexão sobre o que realmente é necessário para que se faça uma alternativa vencedora, ou seja, qual a importância dos critérios. Sem sair dos exemplos esportivos, é possível assinalar um evento que ainda está relativamente presente na memória do povo brasileiro, que foi a Copa do Mundo de 1982 quando a seleção, mesmo dando um show em campo foi eliminada pela Itália.

Sugere-se a mesma pergunta anterior: qual dos dois times jogou melhor. Do ponto de vista Lexicográfico a Itália, com robustas evidências. Mas será que é somente a quantidade de gols que faz uma equipe ser melhor? E o chamado futebol arte? 0 mais correto seria estipular uma 
pontuação para cada tipo de jogada executada, a quantidade de dribles, o número de jogadas ofensivas, as defesas bem feitas etc. Porém, não se pode transformar o futebol em uma série de quantitativa sem graça, pois os times provavelmente passariam a estudar formas seguras de atingir pontuações altas e o jogo perderia o charme. Além do mais, e nos casos que mereçam interpretação? Seria igual a uma luta de boxe na qual os jurados dariam notas para alguns critérios?

Provavelmente, estas sugestões tornariam o futebol mais monótono, além de mais caro, pois as bancas de jurados certamente deverão ser remuneradas. Tem ainda outro problema, pois, se com apenas um juiz já se criam grandes polêmicas, imagine-se com um grupo deles. 0 carnaval carioca já sofreu várias vezes com isso, tantas já foram as agremiações que protestaram contra determinado jurado. Dessa forma, decidiram eliminar a maior e a menor nota, como forma de compensação, porém, o resultado é sempre uma série de empates. É por essa e outras razões que, no caso dos esportes, por mais errado que pareça ser uma equipe ganhar sem jogar melhor, o critério de valoração mais eficiente ainda é o aspecto quantitativo. 0 gol, o ponto, a cesta são certamente as formas menos complicadas de se definir os vitoriosos. Como a maioria dos aspectos da teoria da decisão requer seu próprio paradoxo, este não poderia ser diferente.

O método também é usado em processos de recrutamento e seleção. As empresas necessitam gerenciar o dilema: quanto mais exaustivo o processo mais será a garantia de escolher a melhor pessoa, porém, maior será a espera pelo novo funcionário e o dinheiro envolvido na contratação.

Dessa forma, o método lexicográfico é indicado pois agiliza o processo. Vejamos: 0 primeiro processo é o do recrutamento que envolve as atividades da empresa para captação de candidatos. Esse é o primeiro critério de corte, pois só serão avisados os candidatos das localizadas selecionadas pela empresa, por exemplo, se as vagas em aberto fossem para os estagiários que atuariam nas áreas de administração e finanças, a empresa poderia enviar informativos apenas para alunos de Universidades Federais. Existe muita polemica em relação a essa prática, mas o fato é que as empresas acham mais provável encontrar um candidato mais adequado nessas instituições. Além disso, o grande número de faculdades particulares de administração levaria a um aumento significativo no número de candidatos, encarecendo e retardando o processo. 0 segundo critério é o perfil do candidato apresentado nos currículos que chegaram, ou seja, aqueles que tiverem idade dentro da esperada, que estejam em determinados períodos do curso etc. 0 terceiro critério é a entrevista coletiva. Trata-se da reunião de um grande numero de candidatos em um auditório onde são apresentadas a empresa, o salário e outras informações importantes (o candidato que não se agradar com algo pode se retirar sem se constranger). Nesse momento a empresa pode aproveitar para fazer alguma prova escrita (inglês, conhecimentos gerais, conhecimentos específicos, etc). 0 critério seguinte é a dinâmica de grupo, para avaliar as particularidades psicológicas do candidato. Por fim, virá a entrevista individual com o gerente que está solicitando o estagiário. Como cada uma das etapas tem caráter eliminatório, esse processo se enquadra dentro das prerrogativas do método lexicográfico. Um último destaque em relação ao método refere-se a criação do super-critério. Se no método da dominância não se tem diferença de peso entre os critérios, no lexicográfico cada critério fica tão valorizado ao ponto de ser considerado um super-critério. É comum ouvir pessoas reclamando que determinado candidato (alternativa) era considerada a melhor de todas, porém, ela apenas "perdia" no primeiro critério. Por isso ficou de fora logo no início do processo. 


\section{CONCLUSÕES}

Verificamos que o processo de tomada de decisão constitui-se num dos maiores desafios para os gestores da atualidade. 0 ambiente volátil e carregado de incertezas, a ausência de informações suficientes que permitam delinear corretamente as situações problematizadas, que demandam a decisão, e a elevada carga de subjetividade presente no contexto da decisão, apenas tornam mais aguda a demanda por instrumentos que auxiliem na tomada de decisão.

Uma conclusão possível que se pode chegar a partir desta breve descrição de metodologias de auxílio à decisão é a seguinte: o decisor não deve obedecer ou confiar cegamente numa ou noutra metodologia de suporte à decisão, mas sim, deve ser capaz de ponderar as qualidades e limitações que cada uma delas oferece para o contexto da tomada de decisão, de tal forma que a incerteza seja reduzida ao mínimo possível, e a qualidade da decisão tomada seja incrementada. Dessa forma, não se pode deixar de recomendar que os gerentes e decisores das empresas estejam sempre atentos para as particularidades das ciências da decisão, nos últimos anos a Acadêmica avançou muito com metodologias, conceitos, axiomas e ferramentas, porém, acredita-se que ela ainda tem muito a oferecer aos gestores para que consigam cada vez mais buscar o tão sonhado risco zero.

\section{BIBLIOGRAFIA}

BANA e COSTA C.A. Três convicções fundamentais na prática do apoio à decisão. Revista Pesquisa Operacional, v.13, n.1, junho de 1993.

BANA E COSTA, C. A.; STEWART, T. J.; VANSNICK, J.C. Multicriteria decision analysis: some throughts based on the tutorial and discussion sessions of the esigma meetings. 14th. European Conference on Operational Research, july, 1995.

BANA E COSTA, C. A.; VANSNICK, J.C. Applications of the MACBETH approach in the framework of an additive aggegation model. Journal of Multi-Criteria Decision Analysis, 6, p.107-114, 2000.

COSTA, H.G. Introdução ao Método de Análise Hierárquica (Análise Multicritério no Auxílio À Decisão). Niterói, RJ , Brasil: Helder Gomes Costa. 2002.

CRUZ, E.P; LOPES, L.A.C. Decisão de fomento à empresa de base tecnológica: uma proposta usando multicritério. In: XVIII Encuentro Nacional de Docentes en Investigación Operativa, 2005, Cordoba, Argentina. Anales del XVIII Encuentro Nacional de Docentes en Investigación Operativa. Cordoba: EPIO-AR, 2005.

DIAS, L.M.C.; ALMEIDA, L.M.A.T.; CLÍMACO, J. Apoio multicritério à decisão. Universidade de Coimbra, Faculdade de Economia, Coimbra, Portugal, 1996.

GOMES, E. D. Integração entre sistemas de informação geográfica e métodos multicritério no apoio à decisão espacial. Dissertação de Mestrado em Engenharia de Produção da COPPEUFRJ, Rio de Janeiro, 1999.

GOMES, E.G.; MELLO, J.C.C. B.S. de. Decisões com múltiplos critérios, conceitos básicos e o método Macbeth. Revista Administração e Sociedade, Rio de Janeiro, v.2 n.3, jan-jun, 2000.

GOMES, E.G.; LINS, M.P.E.; SOARES DE MELLO, J.C.C. B. Selecção do melhor município: integração SIG-Multicritério. Revista Investigação Operacional, v. 22, n. 1, p. 59-85, 2002. 
REZENDE S.O. Sistemas Inteligentes: fundamentos e aplicações / organização, Solange Oliveira Rezende. - Barueri, SP: Manole, 2003.

ROY, B.; BOUYSSOU, D., Aide Multicritére à la Décision: Méthodes et Cas, Economica, Paris, 1993.

SAATY, T. L. Método de Análise Hierárquica. tradução de Wainer da Silveira e Silva. São Paulo: Mc Graw - Hill, 1991.

SIMON, H.A. Comportamento administrativo. Rio de Janeiro: Fundação Getúlio Vargas, 1974. 